\title{
Salt-Template Hydrothermal Carbonization for Pd NP- loaded Porous Carbonaceous Material
}

\author{
Jiaming Li, Xiaoyun Li, Guocheng Han, Chuanfu Liu, and Xiaoying Wang* \\ Inorganic salt is a promising stabilizer in the hydrothermal synthesis of \\ porous carbon materials. A three-dimensional palladium-loaded (Pd- \\ loaded) lignin carbonaceous material with a porous structure was \\ developed via hydrothermal carbonization, with lignin as not only a carbon \\ source but also a reducing and stabilizing agent for palladium \\ nanoparticles ( $\mathrm{Pd} \mathrm{NPs}$ ) and then with $\mathrm{LiCl}$ as the hard template and \\ porogen. The porogen-induced Pd-loaded carbonaceous material \\ displayed an orderly pore structure with more porosity than the porogen- \\ free Pd-loaded carbonaceous material. Subsequently, the porogen- \\ induced Pd-loaded carbonaceous materials were transferred to an \\ aqueous phase filter and mixed with reactants in a syringe as catalysts. \\ The catalyst exhibited excellent catalytic performances in the reduction \\ reaction of 4-nitrophenol to 4-aminophenol by $\mathrm{NaBH}_{4}$, with a rate constant \\ of $0.11 \mathrm{~min}^{-1}$, which was higher than that of the porogen-free Pd-loaded \\ carbonaceous material. In this study, $\mathrm{LiCl}$ was employed as the hard \\ template and porogen to construct the porous carbonaceous structure and \\ improve the porosity by stabilizing the pore structure and minimizing \\ collapse, which provided a new way to synthesize lignin porous \\ carbonaceous material.
}

Keywords: LiCl template; Hydrothermal carbonization; Lignin; Pd NP; Catalyst

Contact information: State Key Laboratory of Pulp and Paper Engineering, South China University of Technology, Guangzhou, 510640, China; *Corresponding author: xyw@scut.edu.cn

\section{INTRODUCTION}

Nanocatalysts based on noble metallic nanoparticles (NPs), especially Pd NPs, have drawn research attention for decades because of their unique optical, photochemical, and phase transition properties, remarkably high catalytic activity, and excellent thermal stability. In particular, high catalytic activity results from the efficient hydrogen relay effect of Pd NPs (Bedia et al. 2010; Huang et al. 2010; Coccia et al. 2012), which facilitates the reaction rate of various essential catalysis processes by the surface migration of $\mathrm{H}$ atoms (Kobayashi et al. 2008). Nevertheless, for Pd NPs, the mobility is one of the most common and troublesome problems (Chen et al. 2010), and results in great loss and no recycling of Pd NPs, as well as a subsequent weakening of the catalytic performance (Chen et al. 2010; Fang and Wang 2013). Efforts have been made to immobilize Pd NPs onto various catalyst supports, including films, ceramics, carbons, etc. (Chu et al. 2007; Huang et al. 2008; Chan et al. 2009). Porous carbon materials are the most effective and convenient catalyst support (Bedia et al. 2010) because of their high chemical stability and controllable pore structure (Alatalo et al. 2016), which may confine metal nanoparticles and endow the surface with more catalytic active sites (Fang and Wang 2013; Duan et al. 2014). Therefore, porous 
carbon materials are considered as a promising catalytic support for Pd NPs to reinforce the composites.

Lignin, the main byproduct in the pulp and paper industry, has been used as a precursor for the fabrication of porous carbons and carbonaceous materials in the past few years (García-Mateos et al. 2017). However, there has been no related research on the immobilization of Pd NPs onto lignin-based porous carbon materials. It has been found that lignin can act as a reducing and stabilizing agent to obtain Pd NPs, and it is notable that Pd NPs can be prepared on lignin-based porous carbon materials by adopting lignin waste as not only a green reducing and stabilizing agent (Shen et al. 2014), but also an accessible carbon precursor (Li et al. 2016; Zhang et al. 2016).

Various strategies have been developed for the synthesis of lignin porous carbon and carbonaceous materials, such as pyrolysis (Thangalazhygopakumar et al. 2015; Thines et al. 2017), activation (Xu et al. 2018), the template method (Wu et al. 2015), microwaveassisted method (Mubarak et al. 2014; Noraini et al. 2016; Nizamuddin et al. 2018), and hydrothermal carbonization (HTC) (Nizamuddin et al. 2016; Wang et al. 2017). Direct pyrolysis is generally considered to be a traditional method for fabricating lignin porous carbons (Li et al. 2016; Zhang et al. 2015), while two-step carbonization including the first pre-carbonization step and the subsequent pyrolysis/activation process has gradually become an efficient approach for improving the carbon porosity (Adebisi et al. 2017; Puziy et al. 2018). Numerous researchers have focused on the pyrolysis and activation process. Dozens of activating agents, such as potassium hydroxide (KOH) (Zhang et al. 2016; Guo et al. 2017), potassium bicarbonate $\left(\mathrm{KHCO}_{3}\right)$ (Deng et al. 2016), and phosphoric acid $\left(\mathrm{H}_{3} \mathrm{PO}_{4}\right)$ (Adebisi et al. 2016; García-Mateos et al. 2017), and hard templates, such as $\mathrm{SiO}_{2}$ (Li et al. 2016), have been introduced to produce large numbers of micropores by strong chemical etching and high temperature gasification and thus generate a high specific surface area (SSA) (Benzigar et al. 2018). Some studies have focused on the improvement during the hydrothermal process (Pileidis et al. 2014; Sevilla et al. 2014; Wu et al. 2016). HTC is a thermal treatment of an aqueous solution or dispersion of carbon source, which proceeds at moderate temperature $\left(180\right.$ to $\left.250{ }^{\circ} \mathrm{C}\right)$ under autogenously created pressure at approximately 20 to 30 bar (Adebisi et al. 2017; Chowdhury et al. 2018b). During the HTC process, linkages between the carbohydrate-rich fractions are broken through a series of hydrolysis, condensation, decarboxylation, and dehydration reactions (Adebisi et al. 2016; Chowdhury et al. 2016). As a mild and low-cost pre-carbonization approach, HTC mostly plays a role in the formation and the modification of carbonaceous materials, which is still limited in porosity increasement and requires further improvement (Sangchoom and Mokaya 2015). Carbonaceous materials synthesized in the hydrothermal pre-carbonization process with an improved pore structure and SSA are considered to be more efficient in subsequent pyrolysis and activation reactions because of their larger contact area with activating agents and templates (Liu et al. 2015; Puziy et al. 2018). However, converting lignin waste into hydrothermal carbonaceous materials with higher porosities remains a challenging task because of the intractable molecular structure of lignin (Chowdhury et al. 2018b; Lin and Dence 1992). Also, during HTC, the lignin precursor forms furanic and aromatic units with oxygen-substituted arene-type moieties (Hu et al. 2010; Wikberg et al. 2015) under pressurized water and inevitably becomes converted into irregular carbon spheres that aggregate easily and block the pore tunnel, which adversely affects the industrial scale-up (Zhang and Zhao 2009; Titirici and Antonietti 2010; De et al. 2015). To solve this problem, inorganic salts can be exploited as both hard templates and porogens to improve the porosity by stabilizing the pore structure, minimizing collapse, and 
subsequently endowing the materials with an orderly morphology and accessible tunnels (Fechler et al. 2013; Ming et al. 2013). Furthermore, the inorganic salts template can be eliminated by washing with deionized water without any chemical etching (Lynam et al. 2012).

In this study, a strategy was proposed that incorporates lithium chloride $(\mathrm{LiCl})$ into hydrothermal carbonization for the fabrication of an efficient catalyst, namely Pd NPloaded lignin porous carbonaceous material. The procedure consists of three stages and is illustrated in Fig. 1. First, lignin was utilized as a reducing and stabilizing agent to prepare Pd NP and was also employed as a carbon source to fabricate porous carbonaceous material. Second, lignin/Pd NP composites were carbonized hydrothermally to form $\mathrm{Pd}$ $\mathrm{NP}$-loaded porous carbonaceous material with $\mathrm{LiCl}$ as the hard template and porogen. $\mathrm{LiCl}$ was employed to construct the porous carbonaceous structure and improve the porosity by stabilizing the pore structure and minimizing collapse, which provided a new way to synthesize lignin porous carbonaceous material. Third, a typical catalytic reaction involving the reduction of 4-nitrophenol (4-NP) to 4-aminophenol (4-AP) by sodium borohydride $\left(\mathrm{NaBH}_{4}\right)$ was selected as a model reaction to investigate the catalytic performances of the Pd NP-loaded porous carbonaceous materials. The effect of the $\mathrm{LiCl}$ salt template was then determined by comparison of the morphologies, textural properties, and catalytic performances of the obtained carbonaceous materials.

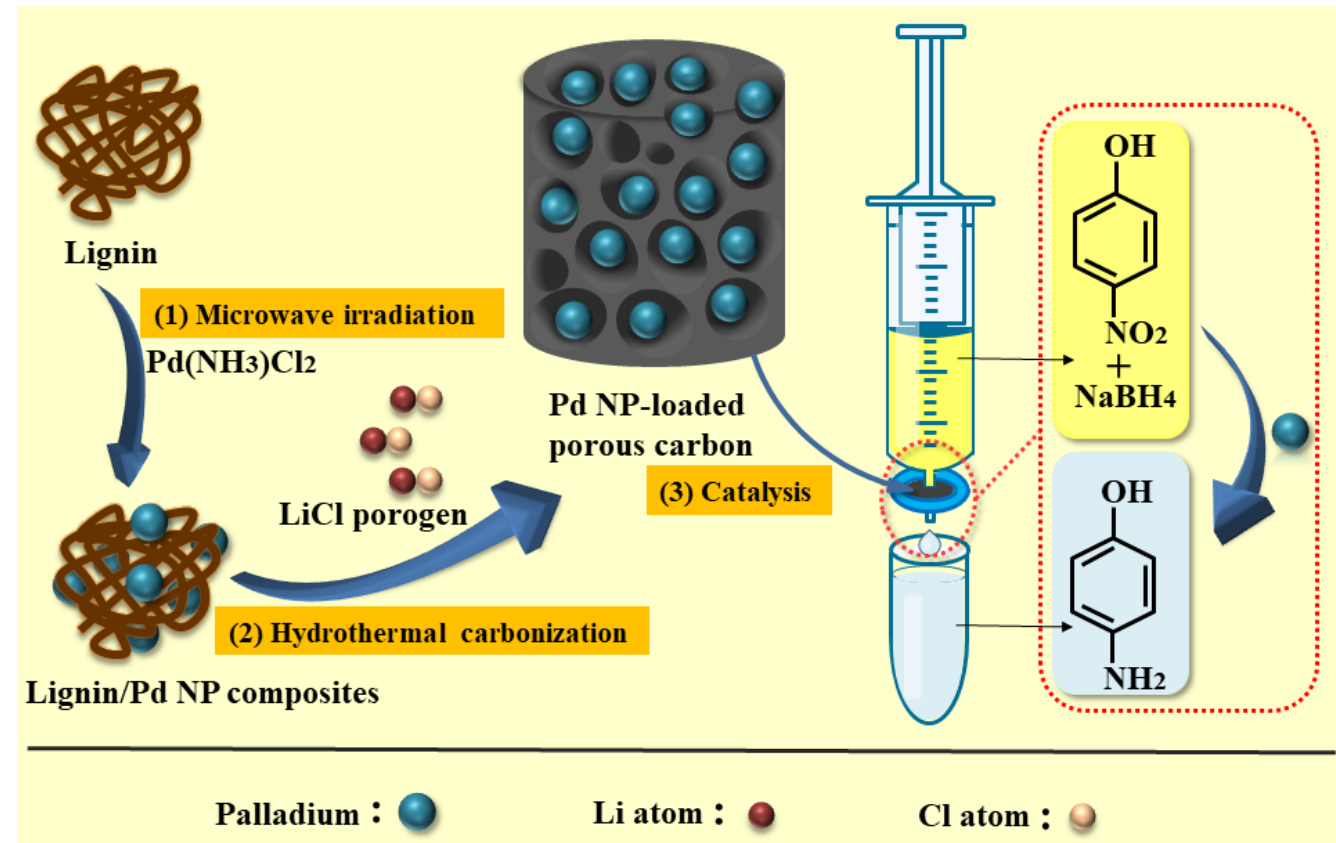

Fig. 1. Preparation of Pd NP-loaded lignin porous carbonaceous material, resulting in application as a catalyst in the reduction of 4-NP to 4-AP by $\mathrm{NaBH}_{4}$

\section{EXPERIMENTAL}

\section{Materials and Apparatus}

The alkali lignin was recovered from soda pulping effluent from the State Key Laboratory of Pulp and Paper Engineering (Guangdong, China) through the alkali extraction and acid precipitation method. It was highly soluble in sodium hydroxide. 
Diammine dichloropalladium (II) $\left(\mathrm{Pd}\left(\mathrm{NH}_{3}\right)_{2} \mathrm{Cl}_{2}\right), 4-\mathrm{NP}$, and lithium chloride ( $\left.\mathrm{LiCl}\right)$ were purchased from Shanghai Macklin Biochemical Co., Ltd (Shanghai, China). Sodium borohydride was acquired from Finechem Group (Zhejiang, China).

Microwave irradiation equipment (XH-100B) was purchased from Beijing Xianghu Sci-Tech Co., Ltd. (Beijing, China). A THC-000 hydrothermal reactor was purchased from Shandong Tianhe Science Center (Shandong, China).

\section{Purification of the Alkali Lignin}

First, the crude alkali lignin was uniformly dispersed in water and an alkali lignin suspension (30 wt $\%$ ) was obtained. Then, $10 \mathrm{wt} \% \mathrm{NaOH}$ was poured into the alkali lignin suspension until the $\mathrm{pH}$ was approximately 13 to 14 to completely dissolve the crude alkali lignin. The mixture was centrifugated and the solution was collected. Then, $12 \%(\mathrm{v} / \mathrm{v}) \mathrm{HCl}$ was slowly poured into the solution at $60{ }^{\circ} \mathrm{C}$, such that the refined lignin was precipitated. The residue was collected and dried at $45^{\circ} \mathrm{C}$ for $36 \mathrm{~h}$.

\section{Synthesis of the Lignin/Pd NP Composites}

The synthesis of the lignin/Pd NP composites was conducted in the lignin solution with the Pd precursor under microwave irradiation. Briefly, the $2 \%$ lignin solution was prepared by dissolving lignin in a $1 \% \mathrm{NaOH}$ solution, and the Pd precursor solution was prepared by dissolving $\mathrm{Pd}\left(\mathrm{NH}_{3}\right)_{2} \mathrm{Cl}_{2}$ in a $2 \% \mathrm{NaOH}$ solution. Then, the lignin solution was added into the Pd precursor solution under microwave irradiation. Finally, the lignin/Pd NP composites were obtained after the resultant solution was dialyzed and freeze-dried at a sublimating temperature of $-40^{\circ} \mathrm{C}$ and a pressure of $0.035 \mathrm{bar}$ for $24 \mathrm{~h}$. The lignin/Pd NP composites were prepared with different ratios of lignin to $\mathrm{Pd}^{2+}$, reaction temperatures, and reaction times (Table $\mathrm{S} 1$ ). The lignin raw material sample was labeled as Lignin, and the lignin/Pd NP composite samples were labeled LigPd1 to LigPd9.

\section{Synthesis of the Pd NP-loaded Lignin Porous Carbonaceous Material}

For the synthesis of the Pd NP-loaded porous carbonaceous material, lignin/Pd NP composites $(3.0 \mathrm{~g}), \mathrm{LiCl}(3.0 \mathrm{~g})$, and deionized water $(15.0 \mathrm{~g})$ were mixed and then autoclaved at $240{ }^{\circ} \mathrm{C}$ for $24 \mathrm{~h}$. The resultant mixture was washed with deionized water to remove residual porogen and then dried under vacuum at $80{ }^{\circ} \mathrm{C}$. This LiCl-induced sample was labeled LigC-Pd-LiCl, while the LiCl-free sample was labeled LigC-Pd.

\section{Characterization}

The X-ray diffraction (XRD) analyses were performed on a D8 Advance Diffractometer system (CuK $\alpha$ radiation, $40 \mathrm{kV}$, and $40 \mathrm{~mA}$ ) from Bruker (Billerica, United States). The diffraction data was recorded using continuous scanning at $3.125 \% \mathrm{~min}$ with a step size of $0.02^{\circ}$. Fourier transform infrared (FT-IR) spectra were obtained on an FT-IR spectrophotometer (TENSOR 27, Bruker). Ultimate analysis (C, H, N, O and S) of the samples was carried out on an Elemental Analyzer (Vario EL cube, Berlin, Germany). Thermogravimetric analysis (TGA) was conducted on a TA Instruments 5500 TGA system to determine the thermal stability of the samples under a $20 \mathrm{~mL} \cdot \mathrm{min}^{-1}$ nitrogen flow. In the TGA analysis, $7 \mathrm{mg}$ of each sample was heated under a $\mathrm{N}_{2}$ flow at $1000{ }^{\circ} \mathrm{C}$ with a heating rate of $10^{\circ} \mathrm{C} \mathrm{min}^{-1}$. The surface morphology was surveyed with a Zeiss Ultra 55 (Carl Zeiss, Oberkochen, Germany) scanning electron microscope (SEM) operating at $5 \mathrm{kV}$ and JEOL JEM-2010 transmission electron microscope (TEM) (Tokyo, Japan) operating at 200 $\mathrm{kV}$. The SEM samples were prepared by embedding the carbon powder onto carbon epoxy 
followed by oven-drying at $60{ }^{\circ} \mathrm{C}$. Before subjected to TEM analysis, the samples were dispersed in ultrapure water, sonicated for $2 \mathrm{~h}$, and then taken up and carefully dropped on an ultra-thin copper mesh grid, followed by drying with an infrared lamp. Nitrogen sorption analysis was conducted with an ASAP 2020 Micromeritics (New York, USA). The samples were degassed at $150{ }^{\circ} \mathrm{C}$ under vacuum for $8 \mathrm{~h}$ before measurements. The specific surface area (SSA) was determined by Brunauer-Emmett-Teller method (BET), and pore size distribution (PSD) was calculated by non-local density functional theory (NLDFT) model. The ultraviolet-visible measurements were performed on a TU-1810 spectrophotometer (Puxi General Equipment Co., Ltd., Beijing, China) with the spectral window ranging from $200 \mathrm{~nm}$ to $600 \mathrm{~nm}$.

\section{Catalytic Activity}

The synthesized Pd-loaded lignin porous carbonaceous materials were tested as catalysts for the reduction of 4-nitrophenol (4-NP) to 4-aminophenol (4-AP) by sodium borohydride $\left(\mathrm{NaBH}_{4}\right)$, which has become a model reaction for evaluation of the catalytic activity of metal NPs (Blosi et al. 2014). The catalytic reduction of 4-NP by $\mathrm{NaBH}_{4} \mathrm{Was}^{-}$ studied in a standard quartz cuvette with a $1-\mathrm{cm}$ path length and approximately $3-\mathrm{mL}$ volume. The obtained Pd NP-loaded porous carbonaceous material was used as a catalyst. The catalysts $(0.01 \mathrm{~g})$ were transferred to an aqueous phase filter. Next, the $\mathrm{NaBH}_{4}$ solution $(1 \mathrm{~mL}$ and $0.12 \mathrm{M})$ and 4-NP solution $(0.5 \mathrm{~mL}$ and $0.005 \mathrm{M})$ were freshly prepared. Then, the above solution was mixed with $60 \mathrm{~mL}$ of distilled water as a reactant. A syringe was used to inject $5 \mathrm{~mL}$ of reactant through the prepared filter with a residence time of $1 \mathrm{~min}$ and the solution was filtered through the catalysts 10 times. An aliquot of the solution was poured into the quartz cuvette, and the absorption spectra were collected using the TU1810 spectrophotometer over the range of $200 \mathrm{~nm}$ to $600 \mathrm{~nm}$.

In the ultraviolet-visible analysis, the 4-NP solution was absorbed at $400 \mathrm{~nm}$, and a second peak appeared at $294 \mathrm{~nm}$ after the addition of the $\mathrm{NaBH}_{4}$ solution. By measuring the change in absorbance at $400 \mathrm{~nm}$ and $294 \mathrm{~nm}$, the catalytic performance of the Pd NPloaded porous carbonaceous material was revealed.

\section{RESULTS AND DISCUSSION}

\section{Characterization of the Pd-loaded Porous Carbon}

The XRD patterns of the lignin/Pd NP composites prepared with different ratios of lignin to $\mathrm{Pd}^{2+}$, reaction times, and reaction temperatures are shown in Fig. S1 (see Appendix). Almost all of the patterns had four peaks at $2 \theta$ values of $39.13^{\circ}, 45.31^{\circ}, 66.53^{\circ}$, and $80.25^{\circ}$, corresponding to the (111), (200), (220), and (311) planes, respectively (Nasrollahzadeh et al. 2016; Kandathil et al. 2018). The diffraction peak at $39.13^{\circ}$ was prominent, while the other peaks were weak, but they still existed. This indicated that $\mathrm{Pd}$ NPs were obtained. After a careful comparison, it was found that with an increase in the $\mathrm{Pd}$ precursor, reaction time, and reaction temperature, the characteristic peaks increased gradually, which indicated the formation of more Pd NPs. Moreover, the FT-IR analysis was performed to evaluate the structural changes of the lignin after the formation of the $\mathrm{Pd}$ NPs. The spectra of the lignin/Pd NP composites prepared with different ratios of lignin to $\mathrm{Pd}^{2+}$, reaction temperatures, and reaction times are exhibited in Fig. S2. The peak at 1708

$\mathrm{cm}^{-1}$, belonging to the absorption of conjugated carbonyl stretching in lignin, disappeared after the reaction, which indicated that the carbonyl groups in the lignin were transformed 
into carboxyl groups by the Pd salts (Ruthiraan et al. 2017; Xiao et al. 2013). The absorption of benzene ring stretching at $1593 \mathrm{~cm}^{-1}, 1510 \mathrm{~cm}^{-1}, 1462 \mathrm{~cm}^{-1}$, and $1420 \mathrm{~cm}^{-1}$, as well as phenolic hydroxyl stretching at $1221 \mathrm{~cm}^{-1}$ became smaller and even disappeared after the reaction (Xiao et al. 2013; Shen et al. 2014). This indicated that phenolic hydroxyl played an important part in the formation of Pd NPs, and formed coordination compounds with the Pd NPs or were removed from the lignin during the reaction (Hu et al. 2014). Furthermore, there was also a slight decrease in the relative band intensities at $1028 \mathrm{~cm}^{-1}$ after the reaction because of aromatic $\mathrm{C}-\mathrm{H}$ deformation of the syringyl and guaiacyl units and aromatic ether ring breathing (Figueiredo et al. 2018). This implied that methylene and methoxy groups were liberated and ether linkages in the lignin structure were cleaved. The decreasing intensities of the bands from the conjugated carbonyl stretching, benzene ring stretching, and phenolic hydroxyl stretching indicated the oxygenation of the lignin by the $\mathrm{Pd}$ salts. From the above explanation, it was concluded that the lignin was decomposed into relatively small molecules with cleavage of the ether linkages and was successfully oxidized by the Pd salts, which acted as a reducing agent in the synthesis of the lignin/Pd composites.

To investigate the influence of carbonization and the $\mathrm{LiCl}$ porogen on the formation of Pd NPs, the obtained carbonaceous materials were characterized by XRD analysis (Fig. 2 ). The pattern in Fig. 2a had four diffraction peaks, which corresponded to the optimum reaction conditions $\left(60 \mathrm{~min}, 80{ }^{\circ} \mathrm{C}\right.$, and $\left.0.5 \mathrm{mg}: 0.5 \mathrm{mmol}\right)$ for the lignin/Pd composites. Figures $2 \mathrm{~b}$ and $2 \mathrm{c}$ show the sample patterns after carbonization with the $\mathrm{LiCl}$ porogen, which had five peaks at $2 \theta$ values of $39.98^{\circ}, 46.52^{\circ}, 68.24^{\circ}, 81.76^{\circ}$, and $86.54^{\circ}$, which corresponded to the (111), (200), (220), (311), and (222) planes of JCPDS (NO. 46-1043), respectively. The diffraction peaks were sharp and intense, which indicated that the Pd NPs were successfully embedded on the prepared carbonaceous materials. Compared with the weak diffraction peak of the lignin/Pd NP composites (Fig. 2a), the strong diffraction peak characteristic of the Pd species in the Pd-loaded porous carbonaceous materials (Figs. 2b and $2 \mathrm{c}$ ) could be interpreted in terms of the incomplete reduction of $\mathrm{Pd}^{2+}$ during microwave irradiation and further reduction of $\mathrm{Pd}^{2+}$ to Pd NPs during the subsequent HTC (Kang et al. 2011). Also, the diffraction peaks of the Pd-loaded porous carbonaceous material (Figs. $2 \mathrm{~b}$ and $2 \mathrm{c}$ ) shifted right compared with the diffraction peaks of the lignin/Pd NP composites (Fig. 2a).

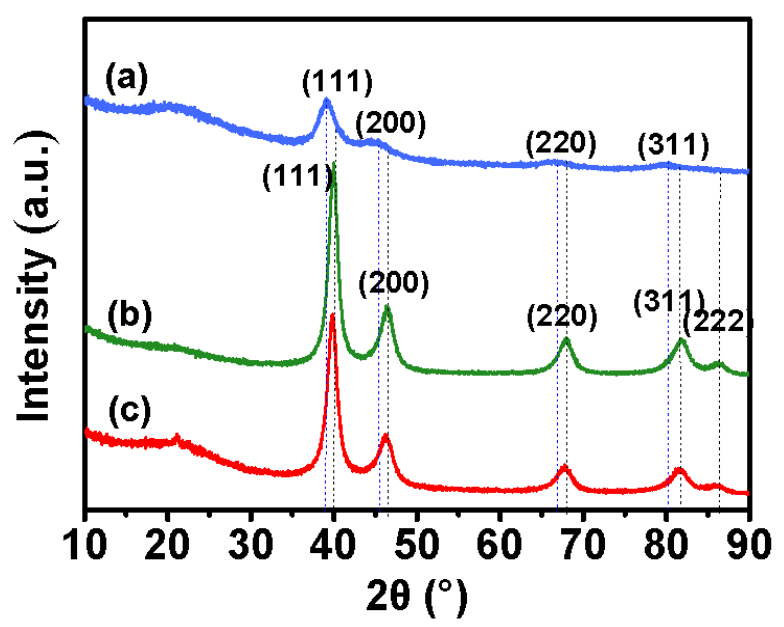

Fig. 2. XRD patterns of the (a) LigPd8, (b) LigC-Pd, and (c) LigC-Pd-LiCl 
This rightward shift of the diffraction peaks might have been related to the cell contraction of the Pd NPs after HTC and resulting decrease in the interlayer spacing of the Pd NPs (Pecharsky and Zavalij 2005). The characteristic peaks of the LigC-Pd-LiCl (Fig. 2c) decreased compared with that of the LigC-Pd (Fig. 2b), which implied that the addition of porogen $\mathrm{LiCl}$ had some influence on the Pd loading of the lignin porous carbonaceous material. One interpretation was that some of the obtained ultrafine Pd NPs were encapsulated in the constructed micropores during the HTC process and concealed within the carbonaceous structure (Calderon et al. 2018), but not all homogeneously dispersed on the carbon surface (Tran et al. 2015), which made them undetectable in the XRD analysis and resulted in a slight decrease in the characteristic peaks.

The morphology and porosity of the prepared Pd NP-loaded porous carbonaceous materials were analyzed by means of a TEM and SEM. Figure 3a shows that the sizes of the Pd NPs were uniform and no larger particle aggregates were observed.
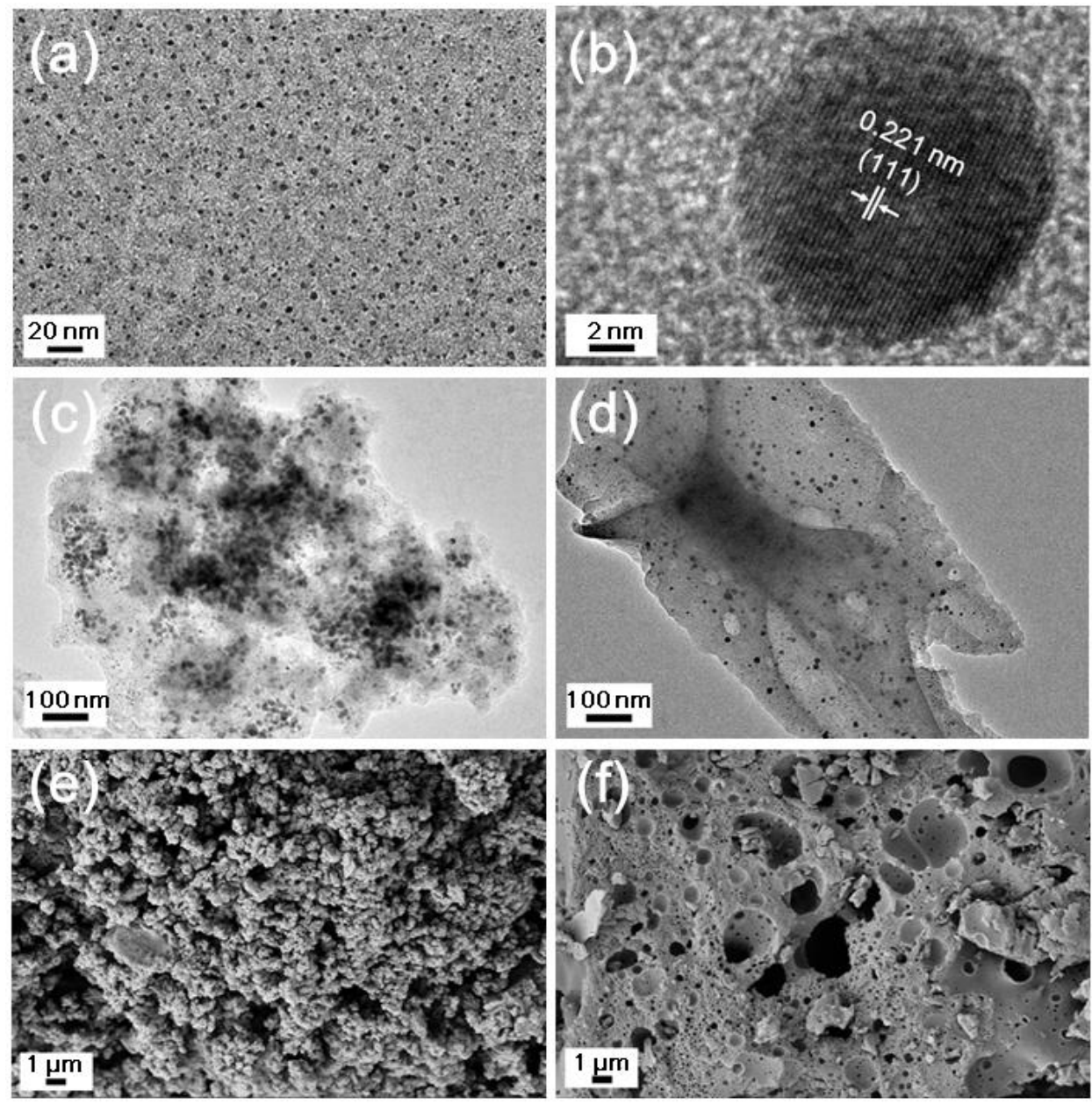

Fig. 3. TEM images of the (a) LigPd8, (b) a single Pd NP, (c) LigC-Pd, and (d) LigC-Pd-LiCl; SEM images of the (e) LigC-Pd and (f) LigC-Pd-LiCl

The high resolution TEM image in Fig. $3 \mathrm{~b}$ revealed that the single Pd nanoparticle was spherical with resolved lattice fringes at a d-spacing of $0.221 \mathrm{~nm}$, which corresponded to a Pd (111) plane and suggested a crystalline structure. This indicated that narrowdispersed Pd NPs were obtained. Figs 3c to $3 f$ show the TEM and SEM images of the LigC- 
Pd and LigC-Pd-LiCl. Particles of the LigC-Pd agglomerated into clusters (Fig. 3c) and the appearance of the LigC-Pd turned out to be irregular lumps (Fig. 3e), whereas no larger particle aggregates of the LigC-Pd-LiCl were observed (Fig. 3d) and the LigC-Pd-LiCl featured an orderly carbon bulk with a high porosity (Fig. 3f). That is to say, the LigC-Pd$\mathrm{LiCl}$ exhibited a stark difference in its carbonaceous structure compared with that of the LigC-Pd. The particles of the LigC-Pd-LiCl were uniformly distributed and those of the LigC-Pd agglomerated into larger particles. In contrast, carbon bulks of the LigC-Pd-LiCl were regularly shaped and possessed an orderly porous structure, while the LigC-Pd appeared to be irregular lumps. The difference in the carbonaceous structure was attributed to the addition of $\mathrm{LiCl}$. The $\mathrm{LiCl}$ salts mixed homogeneously with the lignin/Pd $\mathrm{NP}$ composites, which do not melt at $240{ }^{\circ} \mathrm{C}$, but are soluble in a water medium (Alatalo et al. 2016; Xiaofeng et al. 2013). As a hard template and porogen, $\mathrm{LiCl}$ salts help to form ion pairs or salt clusters during the HTC process so that spherical open voids are obtained in the hydrothermal carbonaceous material after washing with water (Lynam et al. 2012). Therefore, $\mathrm{LiCl}$ can improve the porosity of carbonaceous materials by stabilizing the pore structure and minimizing collapse, which results in an orderly morphology of the prepared materials (Fechler et al. 2013; Ming et al. 2013). Moreover, embedded LiCl lowers the partial pressure of water and changes the carbonaceous structure into a well-pronounced porosity (Lynam et al. 2012).

The SSA and pore structures of the LigC-Pd and LigC-Pd-LiCl were also investigated by nitrogen $\left(\mathrm{N}_{2}\right)$ adsorption/desorption analysis. The $\mathrm{N}_{2}$ adsorption/desorption isotherms and pore size distributions (PSDs) of the prepared carbonaceous samples are shown in Fig. 4. As shown in Fig. 4a, the LigC-Pd exhibited a type IV isotherm with an apparent hysteresis loop, which was indicative of a mesoporous structure. The LigC-Pd$\mathrm{LiCl}$ also showed a type IV isotherm with a higher $\mathrm{N}_{2}$ sorption in the low $P / P_{0}$ range compared with that of the LigC-Pd, which indicated the existence of a mesoporous structure. The pore size distribution curves (Fig. 4b) calculated using the DFT model reveal that the samples mainly consist of abundant micropores $(<2 \mathrm{~nm})$ and small mesopores $(2$ to $6 \mathrm{~nm}$ ). Compared with LigC-Pd, LigC-Pd-LiCl obtained with $\mathrm{LiCl}$ salts led essentially to mesoporous carbonaceous materials with larger pore volumes. Based on the sorption isotherms using the Brunauer-Emmett-Teller theory, the SSAs and porous properties (total pore volume and average pore size) were determined and are summarized in Table 1 . The LigC-Pd had an SSA of $17.49 \mathrm{~m}^{2} / \mathrm{g}$ and total pore volume of $0.01 \mathrm{cc} / \mathrm{g}$. Compared with the LigC-Pd, the LigC-Pd-LiCl showed a higher SSA and total pore volume of $42.08 \mathrm{~m}^{2} / \mathrm{g}$ and $0.05 \mathrm{cc} / \mathrm{g}$, respectively. Also, the steep curve at the beginning of the LigC-Pd $\mathrm{N}_{2}$ adsorption isotherm indicated the presence of microporosity in the internal structure. The presence of micropores was further supported by the pore size of the LigC-Pd, which was $1.53 \mathrm{~nm}$. Accordingly, it was concluded that the LigC-Pd possessed a mesoporous structure with micropores in the internal structure. The LigC-Pd- $\mathrm{LiCl}$ displayed a pore size of $4.67 \mathrm{~nm}$, which was a definite indication of a mesoporous main structure. This was in good agreement with the LigC-Pd-LiCl $\mathrm{N}_{2}$ adsorption isotherm. These findings suggested that $\mathrm{LiCl}$ played an important role in controlling the pore volume of the resultant carbon. With the addition of $\mathrm{LiCl}$, more mesopores were formed, and the pore volume was enlarged from $0.01 \mathrm{cc} / \mathrm{g}$ to $0.05 \mathrm{cc} / \mathrm{g}$. The increase in the pore volume indicated that more Pd NPs would be immobilized in the interior cavities of the porogen-induced porous carbon than the porogen-free carbon (Lynam et al. 2012). Thus, the LigC-Pd-LiCl had a better adsorption capacity. 
Table 1. Textural Properties of the Pd-loaded Lignin Porous Carbonaceous Materials

\begin{tabular}{|c|c|c|c|}
\hline Sample & $\mathbf{S S A}\left(\mathbf{m}^{2} \mathbf{g}\right)$ & $\boldsymbol{V}_{\text {total }}(\mathbf{c c} / \mathbf{g})$ & Pore Size $(\mathbf{n m})$ \\
\hline LigC-Pd & 17.49 & 0.01 & 1.53 \\
\hline LigC-Pd-LiCl & 42.08 & 0.05 & 4.66 \\
\hline
\end{tabular}

$V_{\text {total }}$ - total pore volume

(a)

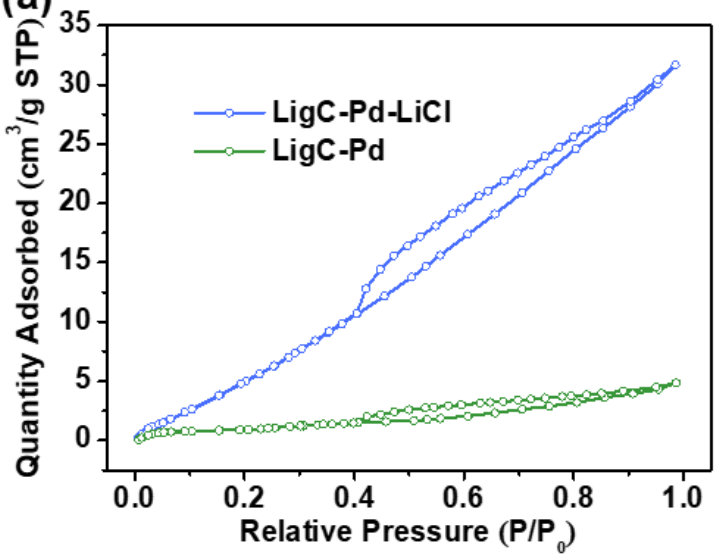

(b)

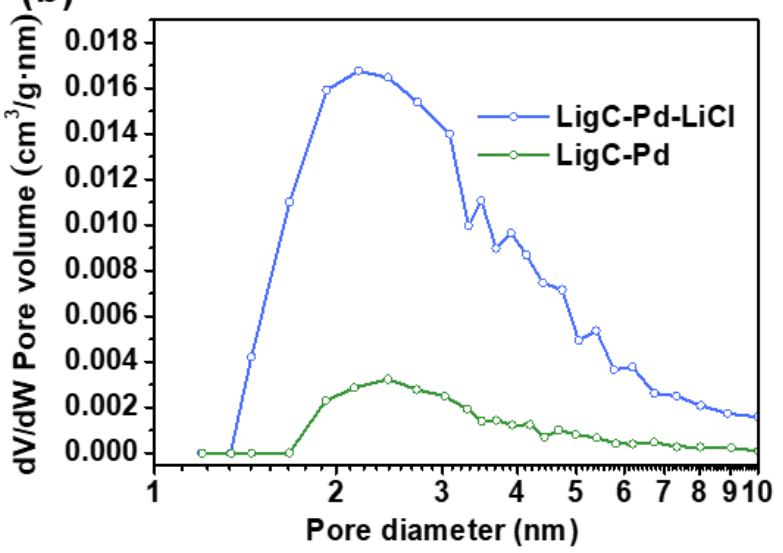

Fig. 4. $\mathrm{N}_{2}$ adsorption isotherms (a) and pore size distributions (PSDs) calculated from the desorption isotherms (b) of the as-prepared carbonaceous materials

Table 2 lists the ultimate analysis of alkali lignin, LigC-Pd and LigC-Pd-LiCl. After hydrothermal carbonization, the carbon content of LigC-Pd and LigC-Pd-LiCl progressively increased, whereas the hydrogen and oxygen contents decreased (Nizamuddin et al. 2017). Compared with the LigC-Pd, the carbon content of LigC-Pd$\mathrm{LiCl}$ further increased after inducing $\mathrm{LiCl}$ salt into the hydrothermal process, while the hydrogen and oxygen contents showed decreasing trends (Adebisi et al. 2016). Both the $\mathrm{H} / \mathrm{C}$ and $\mathrm{O} / \mathrm{C}$ ratios decreased after hydrothermal carbonization and the addition of $\mathrm{LiCl}$ into the hydrothermal process as a result of the decarboxylation and aromatization (Adebisi et al. 2017). The LiCl salt aided in the dehydration, leading to the declining trend of both $\mathrm{H} / \mathrm{C}$ and $\mathrm{O} / \mathrm{C}$ ratios.

Table 2. Ultimate Analysis of Alkali Lignin, LigC-Pd and LigC-Pd-LiCl

\begin{tabular}{|c|c|c|c|}
\hline Ultimate Analysis & Alkali Lignin & LigC-Pd & LigC-Pd-LiCl \\
\hline Carbon (\%) & 55.44 & 64.03 & 69.74 \\
\hline Hydrogen (\%) & 6.78 & 6.17 & 5.15 \\
\hline Nitrogen (\%) & 1.50 & 1.42 & 1.33 \\
\hline Oxygen (\%) & 36.23 & 28.38 & 23.78 \\
\hline H/C & 0.122 & 0.096 & 0.074 \\
\hline O/C & 0.654 & 0.443 & 0.341 \\
\hline
\end{tabular}


Thermal gravimetric analysis (TGA) is employed to study the thermal stability and combustion performance of alkali lignin, LigC-Pd and LigC-Pd-LiCl. The TGA curves are shown in Fig. 5a, and the corresponding DTGs can be seen in Fig. 5b. Lower mass loss was achieved for LigC-Pd (57.61\%) and LigC-Pd-LiCl (57.68\%), while the highest mass loss was for pure alkali lignin $(65.75 \%)$. The thermal degradation curves showed several stages for all the samples. The first degradation step occurred at approximately 60 to 110 ${ }^{\circ} \mathrm{C}$ due to the evaporation of adsorbed moisture. The subsequent degradation steps for alkali lignin proceed within the temperature range of 200 to $800{ }^{\circ} \mathrm{C}$ due to its complex structure (Nizamuddin et al. 2015; Chowdhury et al. 2018a). The combustion of alkali lignin involves mainly combustion of volatiles, which ignited at lower temperature (below 250 ${ }^{\circ} \mathrm{C}$ ) owing to its high reactivity, as shown in Fig. 5b (Nizamuddin et al. 2015). The main weight loss of hydrothermal carbonized samples occurred at 300 to $550{ }^{\circ} \mathrm{C}$ because of the removal of volatile matter, with the mass loss of $41.11 \%$ and $24.83 \%$ for LigC-Pd and LigC-Pd-LiCl, respectively. At higher temperatures in the range of 550 to $1000{ }^{\circ} \mathrm{C}$, mass loss for alkali lignin was $15.8 \%$, whereas in the case of LigC-Pd and LigC-Pd-LiCl it was $17.5 \%$ and $32.0 \%$, respectively, which indicated that the presence of lignin molecular chain made the decomposition much more difficult (Chowdhury et al. 2016). The temperatures at which maximum rate of weight loss occurs are defined by the position of peaks in differential thermal gravity (DTG) curves.

As illustrated by Fig. 5b, DTG $\mathrm{max}_{\text {ax }}$ of alkali lignin, LigC-Pd and LigC-Pd-LiCl were at $364{ }^{\circ} \mathrm{C}, 373{ }^{\circ} \mathrm{C}$, and $391{ }^{\circ} \mathrm{C}$, respectively. Hydrothermal carbonization (HTC) removed most of the volatiles from alkali lignin, leading to an increase of thermal stability in LigC$\mathrm{Pd}$ and LigC-Pd-LiCl samples (Wikberg et al. 2015). With the addition of $\mathrm{LiCl}$ into the HTC process, the obtained sample (LigC-Pd-LiCl) contains a larger proportion of structural stable carbon particles which makes it more heat resistant (Kumar et al. 2016; Chowdhury et al. 2018a). Corresponding to the SEM results, the less heat resistant LigC$\mathrm{Pd}$ agglomerated into irregular lumps, while LigC-Pd-LiCl with better thermal stability exhibited an orderly porous structure. Therefore, $\mathrm{LiCl}$ can improve the porosity of carbonaceous materials by stabilizing the pore structure, which endows the prepared materials with an orderly morphology and also a better thermal stability (Fechler et al. 2013; Ming et al. 2013).
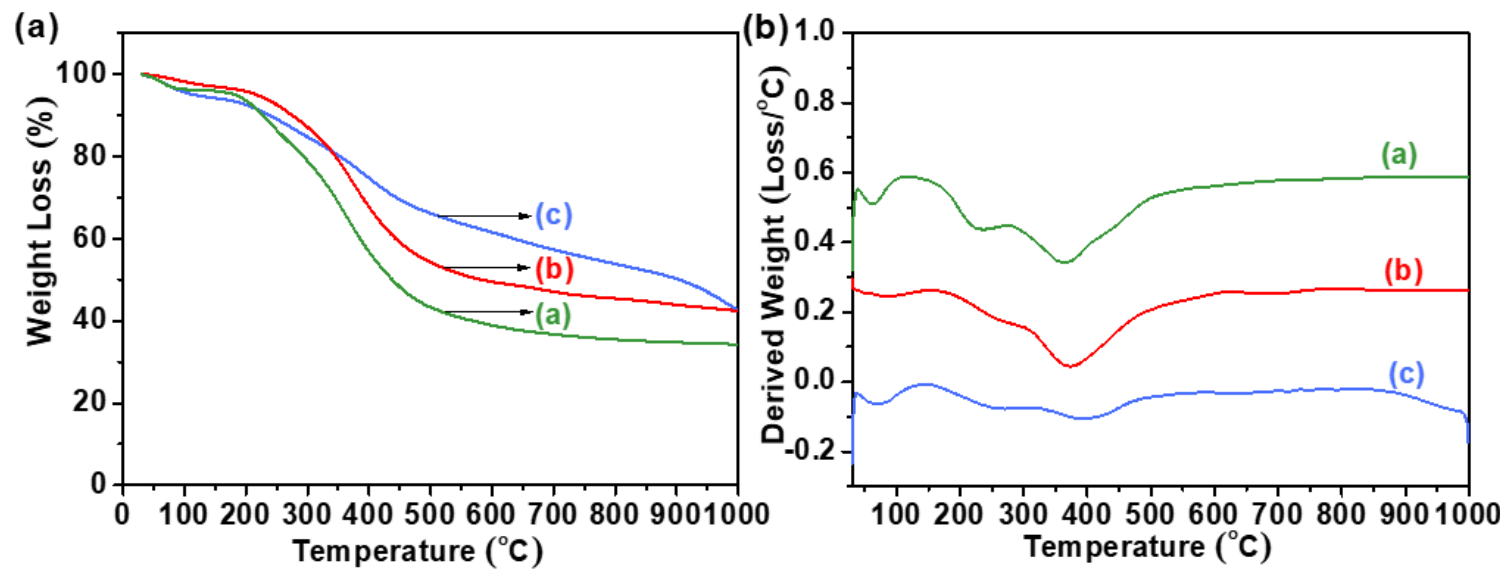

Fig. 5. TGA and DTG profile of (a) alkali lignin (b) LigC-Pd and (c) LigC-Pd-LiCl 
(a)

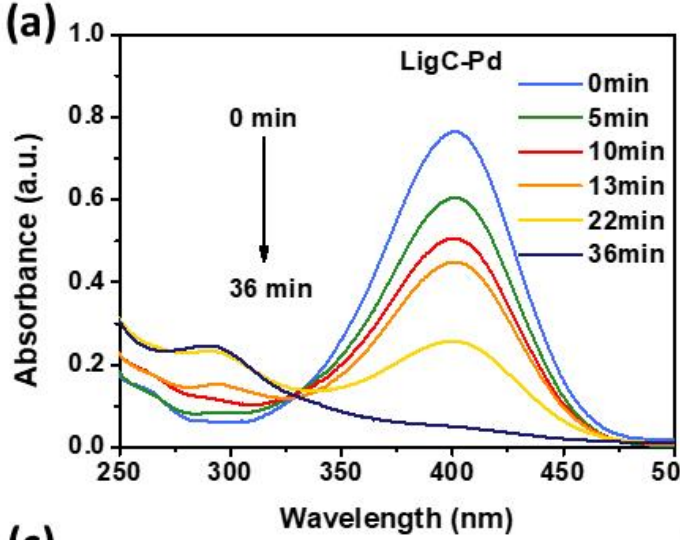

(c)

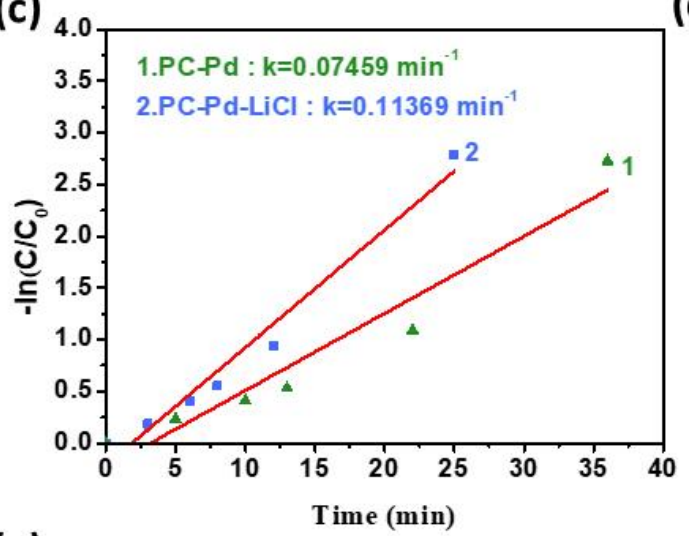

(b)

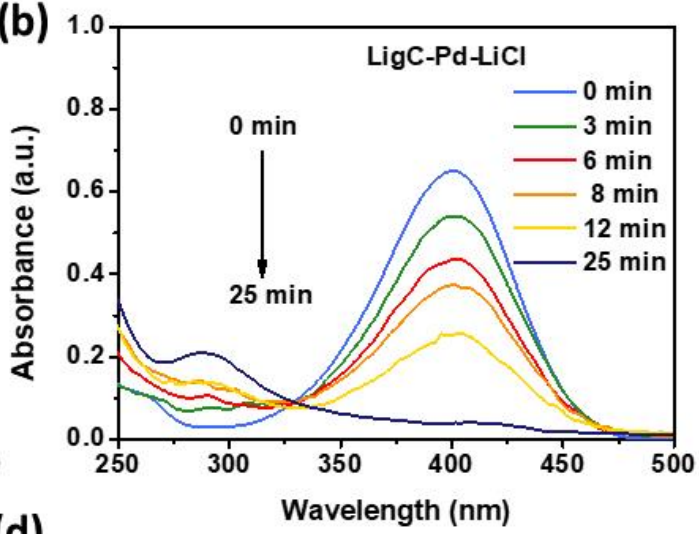

(d)

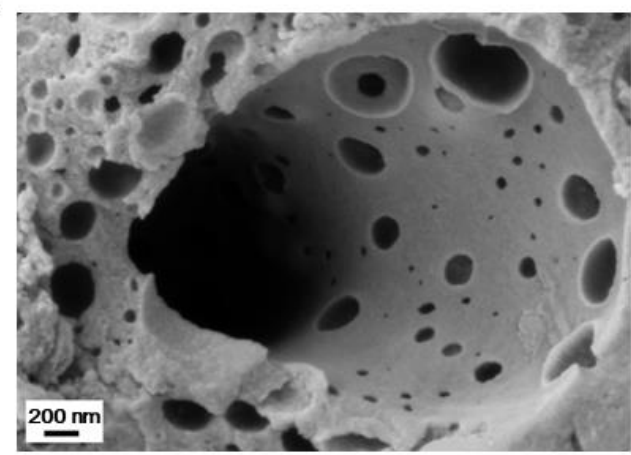

(e)

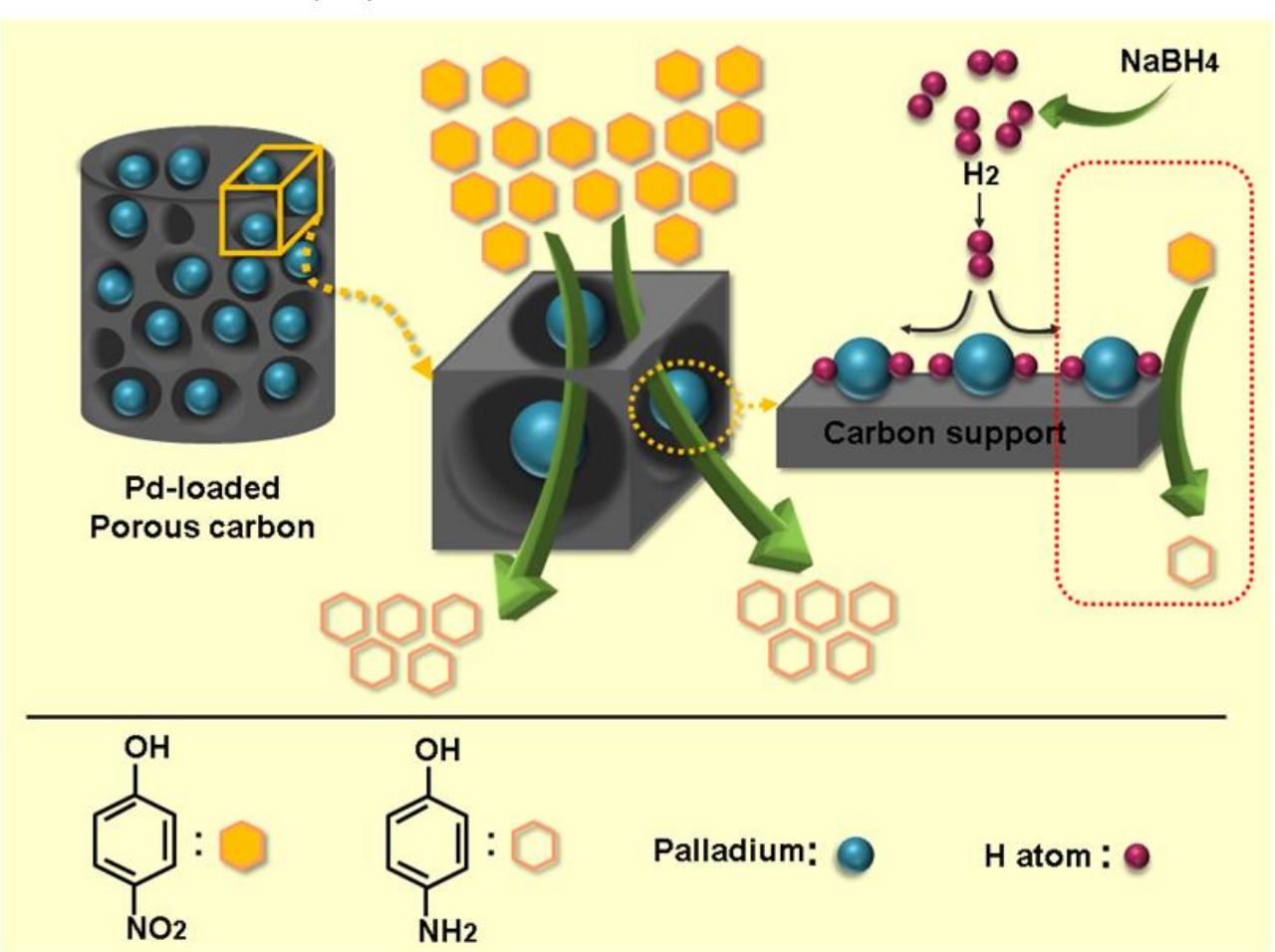

Fig. 6. Catalytic performances of the (a) LigC-Pd and (b) LigC-Pd-LiCl; (c) catalytic reaction rates; (d) SEM image of the LigC-Pd-LiCl after the catalysis; and (e) possible mechanism of LigC-Pd$\mathrm{LiCl}$ production in the 4-NP reduction reaction 


\section{Catalytic Performance}

Figure 6 shows the two degradation spectra of the 4-NP with LigC-Pd and LigC$\mathrm{Pd}-\mathrm{LiCl}$ as catalysts. It was found that the 4-NP absorbance at $400 \mathrm{~nm}$ decreased and the 4-AP absorbance at $294 \mathrm{~nm}$ increased. It took LigC-Pd-LiCl $25 \mathrm{~min}$ to reach equilibrium, which was faster than LigC-Pd. This result indicated that the LigC-Pd-LiCl exhibited a better catalytic performance than the LigC-Pd. The porogen-induced Pd-loaded carbonaceous catalyst had excellent catalytic performances in the reduction reaction of 4$\mathrm{NP}$ to $4-\mathrm{AP}$ by $\mathrm{NaBH}_{4}$, with a rate constant $(k)$ of $0.11 \mathrm{~min}^{-1}$, which was higher than that of the porogen-free carbonaceous material $\left(0.07 \mathrm{~min}^{-1}\right)$. Figure $6 \mathrm{~d}$ shows that the LigC-Pd$\mathrm{LiCl}$ possessed an interconnected porous structure, which helped improve the contact area between the reactants and catalysts. The carbonaceous structure remained stable after catalysis. Additionally, the excellent catalytic performance of the LigC-Pd-LiCl supported the above conclusion that $\mathrm{LiCl}$ played a notable role in the improvement of the morphology and pore structure of the carbonaceous materials.

In the present work, the LigC-Pd-LiCl was used as an efficient catalyst, and it exhibited a high activity in the reduction of 4-NP to 4-AP by $\mathrm{NaBH}_{4}$. The reaction mechanism is shown in Fig. 6e. Generally, for a metal catalyst that embeds onto a catalyst support, a surface migration of activated hydrogen atoms would occur when it is in a $\mathrm{H}_{2}$ atmosphere, which is called hydrogen spillover (Karim et al. 2017). Figure 6e shows that $\mathrm{NaBH}_{4}$ decomposed on the surface of the nanoparticles and produced $\mathrm{H}_{2}$ that transformed into activated $\mathrm{H}$-atoms by $\mathrm{Pd} \mathrm{NPs}$, which were available to the 4-NP molecules sequentially. The simultaneous addition of H-atoms to the 4-NP followed one of the typical mechanisms of heterogeneous reactions, such as the Eley-Rideal or LangmuirHinshelwood reactions (Khalavka et al. 2009; Jin et al. 2016), as marked by the red-dotted square in Fig. 6e. Consequently, in this experiment, the Pd NPs of the lignin porous carbonaceous material acted as an $\mathrm{H}$ carrier, adsorbed hydrogen from $\mathrm{NaBH}_{4}$, and released it during the reduction of 4-NP.

Table 3. Comparison of the Reduction of 4-NP Catalyzed with Different Catalysts

\begin{tabular}{|c|c|c|c|c|}
\hline Catalyst & $\begin{array}{c}\text { Supporting } \\
\text { Material }\end{array}$ & $\begin{array}{l}\text { Reduction } \\
\text { Time (min) }\end{array}$ & $k\left(\min ^{-1}\right)$ & Reference \\
\hline LigC-Pd-LiCl & Lignin & 25 & 0.110 & \multirow{2}{*}{ Present work } \\
\hline LigC-Pd & Lignin & 36 & 0.070 & \\
\hline Pd NPs & Lignin & - & 0.072 & \multirow{3}{*}{ Han et al. (2017) } \\
\hline $\mathrm{Au}$ NPs & Lignin & - & 0.068 & \\
\hline Au-Pd nanoalloys & Lignin & 16 & 0.239 & \\
\hline Pd NPs & $\begin{array}{l}\text { Seed extract of } \\
\text { milk thistle }\end{array}$ & 27 & - & $\begin{array}{c}\text { Gopalakrishnan et al. } \\
\text { (2017) }\end{array}$ \\
\hline Pd-Ni alloy & - & 8 & 0.550 & \multirow{2}{*}{ Revathy et al. (2018a) } \\
\hline $\mathrm{Pd}$ & - & 24 & 0.062 & \\
\hline Pd-GA/RGO & Gum Arabic & 5 & 0.120 & Vilian et al. (2017) \\
\hline $\begin{array}{l}\text { AgNPs@MWCN } \\
\text { Ts-polymer } \\
\text { composite }\end{array}$ & Chitosan & 5 & 0.473 & Alshehri et al. (2016) \\
\hline Pd-Ni alloy & - & 20 & 0.054 & \multirow{3}{*}{ Revathy et al. (2018b) } \\
\hline $\mathrm{Pd}-\mathrm{Ni} / \mathrm{C}$ & $\begin{array}{c}\text { Carbon black } \\
\text { Vulcan XC-72R }\end{array}$ & 18 & 0.142 & \\
\hline $\mathrm{Pd}-\mathrm{Ni} / \mathrm{rGO}$ & Graphene oxide & 12 & 0.160 & \\
\hline Gold NPs & Starch & 13 & 0.033 & Chairam et al. (2017) \\
\hline $\mathrm{Ni} / \mathrm{Carbon}$ & Starch & - & 0.094 & Wu et al. (2018) \\
\hline
\end{tabular}

Li et al. (2019). "Pd-loaded porous material," BioResources 14(2), 3630-3650. 
The LigC-Pd-LiCl provided more active sites to sustain larger quantities of Pd NPs on the skeleton with an orderly porous structure. Moreover, the formed hierarchical pores in the LigC-Pd-LiCl (Fig. 6d) could be used as nanoreactors to increase the contact area between the reactant and catalyst, which has synergistic effects on the catalytic activity. Thus, the LigC-Pd-LiCl exhibited an excellent catalytic activity in the hydrogenation of 4$\mathrm{NP}$ by $\mathrm{NaBH}_{4}$.

Recent reports on the 4-NP reduction using different nanoparticles as catalysts are listed in Table 3. Compared with these reports, the present work using LigC-Pd-LiCl as a single metallic catalyst exhibited an excellent catalytic performance.

\section{CONCLUSIONS}

1. Lignin/Pd nanoparticle (NP) composites were successfully prepared as carbon precursors using lignin as a reducing and stabilizing agent. The preparation factors were optimized and the reaction temperature, time and ratios of lignin to $\mathrm{Pd}^{2+}$ substantially influenced each response variable.

2. A LiCl-induced hydrothermal carbonization (HTC) method was developed to synthesize porous carbonaceous material ( $\mathrm{LigC}-\mathrm{Pd}-\mathrm{LiCl}$ ) from lignin/Pd NPs composites. As a hard template and porogen, $\mathrm{LiCl}$ played a significant role in the construction of porous carbonaceous structure with enhanced specific surface area and abundant mesopores.

3. LigC-Pd-LiCl used as a single metallic catalyst in the reduction of 4-NP to 4-AP exhibited excellent catalytic performance with a rate constant $(k)$ of $0.11 \mathrm{~min}^{-1}$. LigC$\mathrm{Pd}-\mathrm{LiCl}$ with orderly formed pores served as nanoreactors between the reactant and catalyst and the narrow-dispersed Pd NPs acted as an H carrier in the catalysis.

4. This study ultimately provides a porosity-improving technique in pre-carbonization before activation, which is promising to obtain lignin carbonaceous materials with high porosity via synergetic improvements of pre-carbonization and the subsequent activation. As an efficient catalyst, it can also be implemented in catalysis area on industrial scale in the future.

\section{ACKNOWLEDGMENTS}

This work was financially supported by the State Key Laboratory of Pulp and Paper Engineering, China (No. 2017TS04), Science and Technology Planning Project of Guangzhou City (No. 201707010190), the National Natural Science Foundation of China (Nos. 51403069 and 31430092), the Natural Science Foundation of Guangdong Province (No. 2016TQ03Z904), and the Fundamental Research Funds for the Central Universities, SCUT (No. 2017ZX003). Jiaming Li especially wishes to thank Yilong Zhu, who has given her spiritual support in research over the past few years. 


\section{REFERENCES CITED}

Adebisi, G. A., Chowdhury, Z. Z., Hamid, S. B. A., and Ali, E. (2017). "Equilibrium isotherm, kinetic, and thermodynamic studies of divalent cation adsorption onto calamus gracilis sawdust-based activated carbon," BioResources 12(2), 2872-2898. DOI: 10.15376/biores.12.2.2872-2898

Adebisi, G. A., Chowdhury, Z. Z., Hamid, S. B. A., and Ali, E. (2016). "Hydrothermally treated banana empty fruit bunch fiber activated carbon for $\mathrm{Pb}$ (II) and $\mathrm{Zn}$ (II) removal," BioResources 11(4), 9686-9709. DOI: 10.15376/biores.11.4.9686-9709

Alatalo, S.-M., Mäkilä, E., Repo, E., Heinonen, M., Salonen, J., Kukk, E., Sillanpää, M., and Titirici, M.-M. (2016). "Meso- and microporous soft templated hydrothermal carbons for dye removal from water," Green Chem. 18(4), 1137-1146. DOI: $10.1039 / \mathrm{c} 5 \mathrm{gc0} 01796 \mathrm{c}$

Alshehri, S. M., Almuqati, T., Almuqati, N., Al-Farraj, E., Alhokbany, N., and Ahamad, T. (2016). "Chitosan based polymer matrix with silver nanoparticles decorated multiwalled carbon nanotubes for catalytic reduction of 4-nitrophenol," Carbohyd. Polym. 151, 135-143. DOI: 10.1016/j.carbpol.2016.05.018

Bedia, J., Rosas, J. M., Rodríguez-Mirasol, J., and Cordero, T. (2010). “Pd supported on mesoporous activated carbons with high oxidation resistance as catalysts for toluene oxidation," Appl. Catal. B-Environ. 94(1-2), 8-18. DOI:

10.1016/j.apcatb.2009.10.015

Benzigar, M. R., Talapaneni, S. N., Joseph, S., Ramadass, K., Singh, G., Scaranto, J., Ravon, U., Al-Bahily, and K., Vinu, A. (2018). "Recent advances in functionalized micro and mesoporous carbon materials: synthesis and applications," Chem. Soc. Rev. 47, 2680-2721. DOI: $10.1039 / \mathrm{c} 7 \mathrm{cs} 00787 \mathrm{f}$

Blosi, M., Albonetti, S., Ortelli, S., Costa, A. L., Ortolani, L., and Dondi, M. (2014). "Green and easily scalable microwave synthesis of noble metal nanosols (Au, Ag, Cu, Pd) usable as catalysts," New J. Chem. 38(4), 1401-1409. DOI: 10.1039/c3nj00894k

Calderon, B., Smith, F., Aracil, I., and Fullana, A. (2018). "Green synthesis of thin shell carbon-encapsulated iron nanoparticles via hydrothermal carbonization," Acs Sustain. Chem. Eng. 6(6), 7995-8002. DOI: 10.1021/acssuschemeng.8b01416

Chairam, S., Konkamdee, W., and Parakhun, R. (2017). "Starch-supported gold nanoparticles and their use in 4-nitrophenol reduction," J. Saudi Chem. Soc. 21(6), 656-663. DOI: 10.1016/j.jscs.2015.11.001

Chan, C.-C., Chang, C.-C., Hsu, W.-C., Wang, S.-K., and Lin, J. (2009). "Photocatalytic activities of Pd-loaded mesoporous $\mathrm{TiO}_{2}$ thin films," Chem. Eng. J. 152(2-3), 492497. DOI: $10.1016 / j . c e j .2009 .05 .012$

Chen, H., Wei, G., Ispas, A., Hickey, S. G., and Eychmüller, A. (2010). "Synthesis of palladium nanoparticles and their applications for surface-enhanced Raman scattering and electrocatalysis," J. Phys. Chem. C 114(50), 21976-21981. DOI: 10.1021/jp106623y

Chowdhury, Z. Z., Karim, M. Z., Ashraf, M. A., and Khalid, K. (2016). "Influence of carbonization temperature on physicochemical properties of biochar derived from slow pyrolysis of durian wood (Durio zibethinus) sawdust," BioResources 11(2), 3356-3372. DOI: 10.15376/biores.11.2.3356-3372

Chowdhury, Z. Z., Abd Hamid, S. B., Rahman, M., and Rafique, R. (2018a). "Catalytic activation and application of micro-spherical carbon derived from hydrothermal 
carbonization of lignocellulosic biomass: Statistical analysis using Box-Behnken design," RSC Adv. 6, 102680-102694. DOI: 10.1039/C5RA26189A

Chowdhury, Z. Z., Krishnan, B., Sagadevan, S., Rafique, R. F., Hamizi, N. A. B., Abdul Wahab, Y., Khan, A. A., Johan, R. B., Aldouri, Y., and Kazi, S. N. (2018b). "Effect of temperature on the physical, electro-chemical and adsorption properties of carbon micro-spheres using hydrothermal carbonization process," Nanomaterials 8(8), 597. DOI: $10.3390 /$ nano8080597

Chu, S.-Z., Kawamura, H., and Mori, M. (2007). "Fabrication and characteristics of Pd nanoparticles/nanofilms on ceramics toward catalytic electrodes," Electrochim. Acta 53(1), 92-99. DOI: 10.1016/j.electacta.2007.05.078

Coccia, F., Tonucci, L., Bosco, D., Bressan, M., and d'Alessandro, N. (2012). “One-pot synthesis of lignin-stabilised platinum and palladium nanoparticles and their catalytic behaviour in oxidation and reduction reactions," Green Chem. 14(4), 1073-1078. DOI: $10.1039 / \mathrm{c} 2 \mathrm{gc} 16524 \mathrm{~d}$

De, S., Balu, A. M., van der Waal, J. C., and Luque, R. (2015). "Biomass-derived porous carbon materials: Synthesis and catalytic applications," ChemCatChem 7(11), 16081629. DOI: $10.1002 /$ cctc. 201500081

Deng, J., Xiong, T., Wang, H., Zheng, A., and Wang, Y. (2016). "Effects of cellulose, hemicellulose, and lignin on the structure and morphology of porous carbons," ACS Sustain. Chem. Eng. 4(7), 3750-3756. DOI: 10.1021/acssuschemeng.6b00388

Duan, B., Liu, F., He, M., and Zhang, L. (2014). “Ag- $\mathrm{Fe}_{3} \mathrm{O}_{4}$ nanocomposites@ chitin microspheres constructed by in situ one-pot synthesis for rapid hydrogenation catalysis," Green Chem. 16(5), 2835-2845. DOI: 10.1039/c3gc42637h

Fang, Y., and Wang, E. (2013). "Simple and direct synthesis of oxygenous carbon supported palladium nanoparticles with high catalytic activity," Nanoscale 5(5), 1843-1848. DOI: $10.1039 / \mathrm{c} 3 \mathrm{nr} 34004 \mathrm{j}$

Fechler, N., Wohlgemuth, S.-A., Jäker, P., and Antonietti, M. (2013). "Salt and sugar: Direct synthesis of high surface area carbon materials at low temperatures via hydrothermal carbonization of glucose under hypersaline conditions," J. Mater. Chem. A 1(33), 9418-9421. DOI: 10.1039/c3ta10674h

Figueiredo, P., Lintinen, K., Hirvonen, J. T., Kostiainen, M. A., and Santos, H. A. (2018). "Properties and chemical modifications of lignin: Towards lignin-based nanomaterials for biomedical applications," Prog. Mater. Sci. 93, 233-269. DOI: 10.1016/j.pmatsci.2017.12.001

García-Mateos, F. J., Cordero-Lanzac, T., Berenguer, R., Morallón, E., Cazorla-Amorós, D., Rodríguez-Mirasol, J., and Cordero, T. (2017). "Lignin-derived Pt supported carbon (submicron)fiber electrocatalysts for alcohol electro-oxidation," Appl. Catal. B-Environ. 211, 18-30. DOI: 10.1016/j.apcatb.2017.04.008

Gopalakrishnan, R., Loganathan, B., Dinesh, S., and Raghu, K. (2017). "Strategic green synthesis, characterization and catalytic application to 4-nitrophenol reduction of palladium nanoparticles," J. Clust. Sci. 28(4), 2123-2131. DOI: 10.1007/s10876-0171207-z

Guo, N., Li, M., Sun, X., Wang, F., and Yang, R. (2017). "Enzymatic hydrolysis lignin derived hierarchical porous carbon for supercapacitors in ionic liquids with high power and energy densities," Green Chem. 19(11), 2595-2602. DOI: $10.1039 / \mathrm{c} 7 \mathrm{gc00506g}$ 
Han, G., Li, X., Li, J., Wang, X., Zhang, Y. S., and Sun, R. (2017). "Special magnetic catalyst with lignin-reduced Au-Pd nanoalloy," ACS Omega 2(8), 4938-4945. DOI: 10.1021/acsomega.7b00830

Hu, B., Wang, K., Wu, L., Yu, S.-H., Antonietti, M., and Titirici, M.-M. (2010). "Engineering carbon materials from the hydrothermal carbonization process of biomass," Adv. Mater. 22(7), 813-828. DOI: 10.1002/adma.200902812

Hu, L., Pan, H., Zhou, Y., Hse, C.-Y., Liu, C., Zhang, B., and Xu, B. (2014). "Chemical groups and structural characterization of lignin via thiol-mediated demethylation," $J$. Wood Chem. Technol. 34(2), 122-134. DOI: 10.1080/02773813.2013.844165

Huang, J., Liu, Y., Hou, H., and You, T. (2008). "Simultaneous electrochemical determination of dopamine, uric acid and ascorbic acid using palladium nanoparticleloaded carbon nanofibers modified electrode," Biosens. Bioelectron. 24(4), 632-637. DOI: 10.1016/j.bios.2008.06.011

Huang, J., Vongehr, S., Tang, S., Lu, H., and Meng, X. (2010). "Highly catalytic Pd-Ag bimetallic dendrites," J. Phys. Chem. C 114(35), 15005-15010. DOI: 10.1021/jp104675d

Jin, F., Qiang, W., Fan, D., Ma, L., Jiang, D., Xie, J., and Zhu, J. (2016). “Nickel-based xerogel catalysts: Synthesis via fast sol-gel method and application in catalytic hydrogenation of p-nitrophenol to p-aminophenol," Appl. Surf. Sci. 382, 135-143. DOI: 10.1016/j.apsusc.2016.04.125

Kandathil, V., Dateer, R. B., Sasidhar, B. S., Patil, S. A., and Patil, S. A. (2018). "Green synthesis of palladium nanoparticles: Applications in aryl halide cyanation and hiyama cross-coupling reaction under ligand free conditions," Catal. Lett. 148(3), 117. DOI: $10.1007 / \mathrm{s} 10562-018-2369-5$

Kang, W., Li, H., Yan, Y., Xiao, P., Zhu, L., Tang, K., Zhu, Y., and Qian, Y. (2011). "Worm-like palladium/carbon core-shell nanocomposites: One-step hydrothermal reduction-carbonization synthesis and electrocatalytic activity," J. Phys. Chem. C 115(14), 6250-6256. DOI: 10.1021/jp111702s

Karim, W., Spreafico, C., Kleibert, A., Gobrecht, J., Van deVondele, J., Ekinci, Y., and van Bokhoven, J. A. (2017). "Catalyst support effects on hydrogen spillover," Nature 541(7635), 68-71. DOI: 10.1038/nature20782

Khalavka, Y., Becker, J., and Sönnichsen, C. (2009). "Synthesis of rod-shaped gold nanorattles with improved plasmon sensitivity and catalytic activity," J. Am. Chem. Soc. 131(5), 1871-1875. DOI: 10.1021/ja806766w

Kobayashi, H., Yamauchi, M., Kitagawa, H., Kubota, Y., Kato, K., and Takata, M. (2008). "On the nature of strong hydrogen atom trapping inside Pd nanoparticles," $J$. Am. Chem. Soc. 130(6), 1828-1829. DOI: 10.1021/ja7102372

Kumar, K. V., Gadipelli, S., Preuss, K., Porwal, H., Zhao, T., Guo, Z. X., and Titirici, M. M. (2016). "Salt templating with pore padding: Hierarchical pore tailoring towards functionalised porous carbons," ChemSusChem 10(1), 199-209. DOI: 10.1002/cssc. 201601195

Li, H., Yuan, D., Tang, C., Wang, S., Sun, J., Li, Z., Tang, T., Wang, F., Gong, H., and He, C. (2016). "Lignin-derived interconnected hierarchical porous carbon monolith with large areal/volumetric capacitances for supercapacitor," Carbon 100, 151-157. DOI: $10.1016 /$ j.carbon.2015.12.075

Lin, S. Y., and Dence, C. W. (1992). Methods in Lignin Chemistry, Springer-Verlag, Berlin, Germany. 
Liu, W.-J., Jiang, H., and Yu, H.-Q. (2015). "Thermochemical conversion of lignin to functional materials: A review and future directions," Green Chem. 17(11), 48884907. DOI: 10.1039/c5gc01054c

Lynam, J. G., Reza, M. T., Vasquez, V. R., and Coronella, C. J. (2012). "Effect of salt addition on hydrothermal carbonization of lignocellulosic biomass," Fuel 99, 271273. DOI: 10.1016/j.fuel.2012.04.035

Ming, J., Wu, Y., Liang, G., Park, J.-B., Zhao, F., and Sun, Y.-K. (2013). "Sodium salt effect on hydrothermal carbonization of biomass: A catalyst for carbon-based nanostructured materials for lithium-ion battery applications," Green Chem. 15(10), 2722-2726. DOI: 10.1039/c3gc40480c

Mubarak, N. M., Kundu, A., Sahu, J. N., Abdullah, E. C., and Jayakumar, N. S. (2014). "Synthesis of palm oil empty fruit bunch magnetic pyrolytic char impregnating with FeCl3 by microwave heating technique," Biomass Bioenerg. 61(2), 265-275. DOI: 10.1016/j.biombioe.2013.12.021

Nasrollahzadeh, M., Sajadi, S.M., Rostami-Vartooni, A., Alizadeh, M., and Bagherzadeh, M. (2016). "Green synthesis of the Pd nanoparticles supported on reduced graphene oxide using barberry fruit extract and its application as a recyclable and heterogeneous catalyst for the reduction of nitroarenes," J. Colloid. Interf. Sci. 466(5), 360-368. DOI: 10.1016/j.jcis.2015.12.036

Nizamuddin, S., Baloch, H. A., Griffin, G. J., Mubarak, N. M., Bhutto, A. W., Abro, R., Mazari, S. A., and Ali, B. S. (2017). "An overview of effect of process parameters on hydrothermal carbonization of biomass,” Renew. Sust. Energ. Rev. 73, 1289-1299.

DOI: 10.1016/j.rser.2016.12.122

Nizamuddin, S., Jayakumar, N. S., Sahu, J. N., Ganesan, P., Bhutto, A. W., and Mubarak, N. M. (2015). "Hydrothermal carbonization of oil palm shell," Korean. J. Chem. Eng. 32(9), 1789-1797. DOI: 10.1007/s11814-014-0376-9

Nizamuddin, S., Mubarak, N. M., Tiripathi, M., Jayakumar, N. S., Sahu, J. N., and Ganesan, P. (2016). "Chemical, dielectric and structural characterization of optimized hydrochar produced from hydrothermal carbonization of palm shell," Fuel 163, 8897. DOI: 10.1016/j.fuel.2015.08.057

Nizamuddin, S., Siddiqui, M. T. H., Baloch, H. A., Mubarak, N. M., Griffin, G., Madapusi, S., and Tanksale, A. (2018). "Upgradation of chemical, fuel, thermal, and structural properties of rice husk through microwave-assisted hydrothermal carbonization," Environ. Sci. Pollut. R. 25(18), 1-11. DOI: 10.1007/s11356-0181876-7

Noraini, M. N., Abdullah, E. C., Othman, R., and Mubarak, N. M. (2016). "Single-route synthesis of magnetic biochar from sugarcane bagasse by microwave-assisted pyrolysis," Mater. Lett. 184, 315-319. DOI: 10.1016/j.matlet.2016.08.064

Pecharsky, V. K., and Zavalij, P. Y. (2005). Fundamentals of Powder Diffraction and Structural Characterization of Materials, Springer US, Boston, MA.

Pileidis, F. D., Tabassum, M., Coutts, S., and Ttitirici, M. M. (2014). "Esterification of levulinic acid into ethyl levulinate catalysed by sulfonated hydrothermal carbons," Chinese J. Catal. 35(6), 929-936. DOI: 10.1016/S1872-2067(14)60125-X

Puziy, A. M., Poddubnaya, O. I., and Sevastyanova, O. (2018). "Carbon materials from technical lignins: Recent advances," Top. Curr. Chem. 376(4), 33. DOI: 10.1007/s41061-018-0210-7

Revathy, T. A., Dhanapal, K., Dhanavel, S., Narayanan, V., and Stephen, A. (2018a). "Pulsed electrodeposited dendritic Pd-Ni alloy as a magnetically recoverable 
nanocatalyst for the hydrogenation of 4-nitrophenol," J. Alloy. Compd. 735, 1703-

1711. DOI: $10.1016 /$ j.jallcom.2017.11.264

Revathy, T. A., Dhanavel, S., Sivaranjani, T., Narayanan, V., Maiyalagan, T., and Stephen, A. (2018b). "Highly active graphene-supported palladium-nickel alloy nanoparticles for catalytic reduction of 4-nitrophenol," Appl. Surf. Sci. 449, 764-771. DOI: $10.1016 / \mathrm{j}$. apsusc.2018.01.280

Ruthiraan, M., Abdullah, E. C., Mubarak, N. M., and Noraini, M. N. (2017). “A promising route of magnetic based materials for removal of cadmium and methylene blue from waste water," J. Environ. Chem. Eng. 5(2), 1447-1455. DOI:

10.1016/j.jece.2017.02.038

Sangchoom, W., and Mokaya, R. (2015). "Valorization of lignin waste: Carbons from hydrothermal carbonization of renewable lignin as superior sorbents for $\mathrm{CO}_{2}$ and hydrogen storage," ACS Sustain. Chem. Eng. 3(7), 1658-1667. DOI: 10.1021/acssuschemeng.5b00351

Sevilla, M., Yu, L., Li, Z., Ania, C. O., and Titiricic, M. M. (2014). "Surface modification of CNTs with N-doped carbon: An effective way of enhancing their performance in supercapacitors," ACS Sustain. Chem. Eng. 2(4), 1049-1055. DOI: $10.1021 / \mathrm{sc} 500069 \mathrm{~h}$

Shen, Z., Luo, Y., Wang, Q., Wang, X., and Sun, R. (2014). "High-value utilization of lignin to synthesize Ag nanoparticles with detection capacity for $\mathrm{Hg}^{2+}$," ACS Appl. Mater. Inter. 6(18), 16147-16155. DOI: 10.1021/am504188k

Thangalazhygopakumar, S., Alnadheri, W. M. A., Jegarajan, D., Sahu, J. N., Mubarak, N. M., and Nizamuddin, S. (2015). "Utilization of palm oil sludge through pyrolysis for bio-oil and bio-char production," Bioresour. Technol. 178, 65-69. DOI: 10.1016/j.biortech.2014.09.068

Thines, K. R., Abdullah, E. C., Mubarak, N. M., and Ruthiraan, M. (2017). "In-situ polymerization of magnetic biochar - polypyrrole composite: A novel application in supercapacitor," Biomass Bioenerg. 98, 95-111. DOI:

10.1016/j.biombioe.2017.01.019

Titirici, M.-M., and Antonietti, M. (2010). "Chemistry and materials options of sustainable carbon materials made by hydrothermal carbonization," Chem. Soc. Rev. 39(1), 103-116. DOI: 10.1039/b819318p

Tran, T., Si, B., Kim, Y., Kim, S., and Lee, H. (2015). "Facile and green cinchonidineassisted synthesis of ultrafine and well-dispersed palladium nanoparticles supported on activated carbon with high catalytic performance," $R S C A d v$. 5(92), 75272-75280. DOI: 10.1039/C5RA10995G

Vilian, A. T., Choe, S. R., Giribabu, K., Jang, S.-C., Roh, C., Huh, Y. S., and Han, Y.-K. (2017). "Pd nanospheres decorated reduced graphene oxide with multi-functions: Highly efficient catalytic reduction and ultrasensitive sensing of hazardous 4nitrophenol pollutant," J. Hazard. Mater. 333, 54-62. DOI: 10.1016/j.jhazmat.2017.03.015

Wang, J., Nie, P., Ding, B., Dong, S., Hao, X., Dou, H., and Zhang, X. (2017). “Biomass derived carbon for energy storage devices," J. Mater. Chem. A 5(6), 2411-2428. DOI: 10.1039/C6TA08742F

Wikberg, H., Ohra-Aho, T., Pileidis, F. D., and Titirici, M. M. (2015). "Structural and morphological changes in kraft lignin during hydrothermal carbonization," ACS Sustain. Chem. Eng. 3(11), 2737-2745. DOI: 10.1021/acssuschemeng.5b00925 
Wu, Q., Wei, L., Liu, S., and Jin, C. (2016). "Hydrothermal synthesis of N-doped spherical carbon from carboxymethylcellulose for $\mathrm{CO}_{2}$ capture," Appl. Surf. Sci. 369, 101-107. DOI: 10.1016/j.apsusc.2016.02.022

Wu, Q., Wei, L., Wu, Y., Zong, G., and Liu, S. (2015). "Effect of reaction time on structure of ordered mesoporous carbon microspheres prepared from carboxymethyl cellulose by soft-template method," Ind. Crop. Prod. 76, 866-872. DOI: 10.1016/j.indcrop.2015.07.047

Wu, Q., Zhang, G., Ma, G., Liu, S., Xie, C., Yu, H., Liu, Y., Huang, L., and Yu, S. (2018). "Carbon composite materials with ordered mesoporous structures from straw: hydrothermal preparation and application as catalysts," Nanotechnology 29, 385604385612. DOI: 10.1088/1361-6528/aacf57

Xiao, L.-P., Shi, Z.-J., Xu, F., and Sun, R.-C. (2013). "Characterization of lignins isolated with alkaline ethanol from the hydrothermal pretreated Tamarix ramosissima," Bioenerg. Res. 6(2), 519-532. DOI: 10.1007/s12155-012-9266-3

Xiaofeng, L., Nina, F., and Markus, A. (2013). "Salt melt synthesis of ceramics, semiconductors and carbon nanostructures," Chem. Soc. Rev. 42(21), 8237-8265. DOI: $10.1039 / \mathrm{C} 3 \mathrm{CS} 60159 \mathrm{E}$

$\mathrm{Xu}, \mathrm{W}$., Li, X., and Shi, J. (2018). "Activation of cellulosic ethanol lignin by laccase and its application as plywood adhesive," BioResources 13(2). DOI: 10.15376/biores.13.2.3005-3016

Zhang, L. L., and Zhao, X. S. (2009). "Carbon-based materials as supercapacitor electrodes," Chem. Soc. Rev. 38(9), 2520-2531. DOI: 10.1039/b813846j

Zhang, W., Lin, H., Lin, Z., Yin, J., Lu, H., Liu, D., and Zhao, M. (2015). “3D hierarchical porous carbon for supercapacitors prepared from lignin through a facile template-free method," ChemSusChem, 8(12), 2114-2122. DOI: 10.1002/cssc. 201403486

Zhang, L., You, T., Zhou, T., Zhou, X., and Xu, F. (2016). "Interconnected hierarchical porous carbon from lignin-derived byproducts of bioethanol production for ultra-high performance supercapacitors," ACS Appl. Mater. Inter. 8(22), 13918-13925. DOI: 10.1021/acsami.6b02774

Article submitted: December 16, 2018; Peer review completed: February 24, 2019; Revised version received and accepted: March 13, 2019; Published: March 19, 2019. DOI: 10.15376/biores.14.2.3630-3650 


\section{APPENDIX}

\section{SUPPLEMENTARY INFORMATION}

Table S1. Lignin/Pd NP Composites with Different Reaction Conditions

\begin{tabular}{|c|c|c|c|}
\hline Samples & Lignin: $\mathrm{Pd}^{2+}(\mathrm{mg} / \mathrm{mmol})$ & $\mathrm{T}\left({ }^{\circ} \mathrm{C}\right)$ & $t(\min )$ \\
\hline Lignin & 1 & 1 & 1 \\
\hline LigPd1 & $1: 1$ & 80 & 10 \\
\hline LigPd2 & $1: 1$ & 80 & 30 \\
\hline LigPd3 & $1: 1$ & 80 & 60 \\
\hline LigPd4 & $1: 1$ & 80 & 90 \\
\hline LigPd5 & $2: 1$ & 80 & 60 \\
\hline LigPd6 & $5: 1$ & 80 & 60 \\
\hline LigPd7 & $1: 1$ & 70 & 60 \\
\hline LigPd8 & $1: 1$ & 90 & 60 \\
\hline LigPd9 & $2: 1$ & 90 & 60 \\
\hline
\end{tabular}
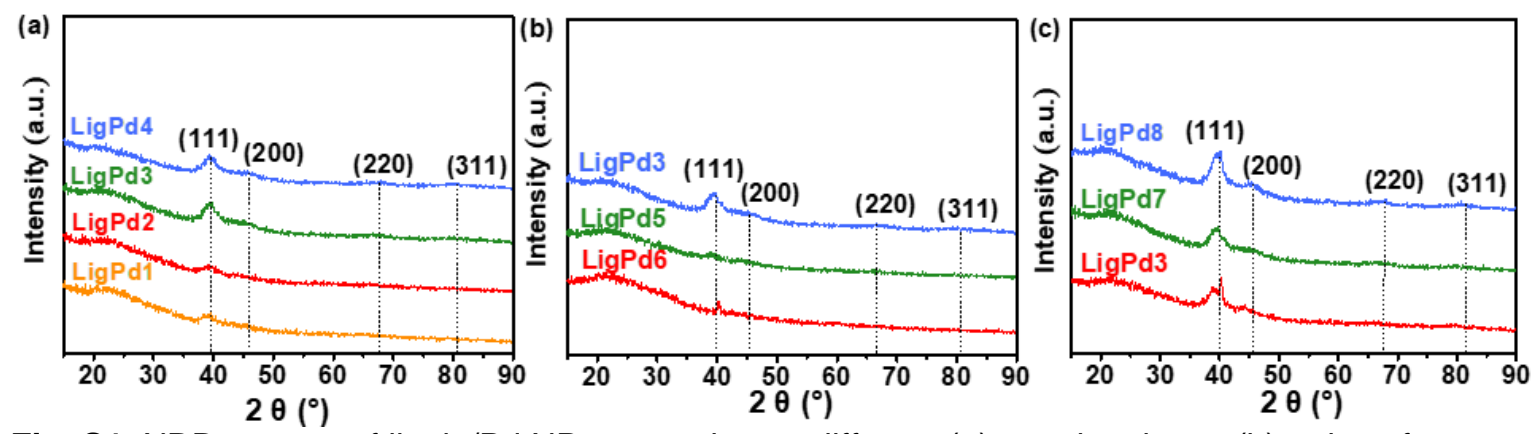

Fig. S1. XRD spectra of lignin/Pd NP composites at different (a) reaction times, (b) ratios of lignin: $\mathrm{Pd}^{2+}$, and (c) reaction temperatures

The different peaks in lignin/Pd NP composites correspond to the (111), (200), (220), and (311) lattice planes of Pd, indicating the formation of Pd nanoparticles. As the reaction time increased, the characteristic peak heights also increased gradually, indicating more Pd NPs in the sample. With an increase in the amount of Pd precursor, the characteristic peaks intensified, indicating the formation of more Pd nanoparticles. With increasing reaction temperature, the characteristic peak heights also increased, demonstrating the generation of more Pd NPs in the sample. When the ratio of lignin: $\mathrm{Pd}^{2+}$ was $1 \mathrm{mg}: 1 \mathrm{mM}$ and the reaction time and temperature were $60 \mathrm{~min}$ and $80^{\circ} \mathrm{C}$, respectively, the optimum lignin/Pd NP composites were obtained. 


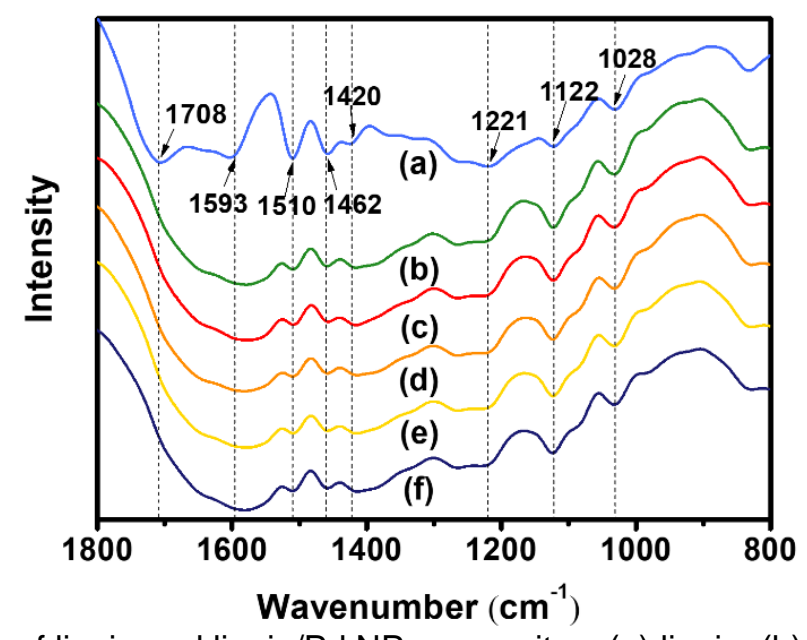

Fig. S2. FT-IR spectra of lignin and lignin/Pd NP composites: (a) lignin, (b) LigPd7, (c) LigPd6, (d) LigPd3, (e) LigPd9, and (f) LigPd8

The decreasing intensities of bands from the reducing functional groups indicate the oxygenation of lignin. The peak at $1708 \mathrm{~cm}^{-1}$ in Fig. S2a, belonging to the absorption of conjugated carbonyl stretching in lignin, disappeared after the reaction, which indicated that the carbonyl groups in lignin may be transformed to carboxyl groups by Pd salts (Xiao et al. 2013). Additionally, the peaks associated with absorption of benzene ring stretching at $1593,1510,1462$, and $1420 \mathrm{~cm}^{-1}$ as well as phenolic hydroxyl stretching at $1221 \mathrm{~cm}^{-1}$ became lower and even disappeared after the reaction (Xiao et al. 2013; Shen et al. 2014). This indicated that phenolic hydroxyl may play an important part in the formation of $\mathrm{Pd}$ NPs, forming coordination compounds with Pd NPs or dropping out from lignin during the reaction (Hu et al. 2014). There was also a slight decrease in the relative band intensities at $1028 \mathrm{~cm}^{-1}$ after the reaction because of the aromatic $\mathrm{C}-\mathrm{H}$ deformation of the syringyl and guaiacyl units and aromatic ether ring breathing (Figueiredo et al. 2018). This result implies the liberation of methylene and methoxy groups and a cleavage of the ether linkages. After the reaction, the FT-IR results of lignin/Pd NP composites prepared under various conditions were almost the same, which may contribute to the higher ratio of lignin to $\mathrm{Pd}^{2+}$. Therefore, subtle changes in the lignin structure in different reaction conditions make little difference in the FT-IR analysis. 